\title{
An Alternative Path for the Preparation of Triacetylcellulose from Unrefined Biomass
}

\author{
Hee Kyung Lim¹, Ha Young Song1, Dal Rye Kim¹, Jeong Ho Ko', Sun Ah Lee1, Kee-In Lee1,2, \\ In Taek Hwang1,2* \\ ${ }^{1}$ Biorefinery Research Group, Green Chemistry Division, Korea Research Institute of Chemical Technology, \\ Daejeon, Republic of Korea \\ ${ }^{2}$ Department of Green Chemistry and Environmental Biotechnology, University of Science \& Technology, \\ Daejeon, Republic of Korea \\ Email: ${ }^{\text {ithwang@krict.re.kr }}$
}

Received 30 September 2014; revised 21 October 2014; accepted 4 November 2014

Copyright (C) 2015 by authors and Scientific Research Publishing Inc.

This work is licensed under the Creative Commons Attribution International License (CC BY).

http://creativecommons.org/licenses/by/4.0/

(c) () D Den Access

\section{Abstract}

An alternative path for the preparation of triacetylcellulose (TAC) from unrefined biomass Palm Empty Fruit Bunch (EFB) has been found with environmental benefits. The method comprises separation and regeneration of cellulose from lignocellulosic biomass dissolved in ionic liquid BMIMCl, and also modification of cellulose to TAC. The triacetylcellulose with a degree of substitution of 2.93 was obtained by the reaction of acetic anhydride at $55^{\circ} \mathrm{C}$ with drastically reducing number of steps currently required to produce this derivative from raw materials itself. TAC was characterized using NMR analysis. The triacetate cellulose is typically used for the creation of fibers and film base.

\section{Keywords}

Ionic Liquid, Palm Empty Fruit Bunch (EFB), Triacetylcellulose (TAC)

\section{Introduction}

One of the major current challenges to the chemical industry is the efficient use of renewable lignocellulosic biomass for the production of performance materials, platform chemicals and biofuels in the so-called "Integrated Biorefinery". Lignocellulosic biomass is a permanent and woefully underutilized source of renewable feedstock with the principal renewable biopolymer forms being cellulose, hemicelluloses, and lignin. A facilitated and more efficient access to natural biopolymers and subsequent enabling of a fuels or materials technolo-

${ }^{*}$ Corresponding author.

How to cite this paper: Lim, H.K., Song, H.Y., Kim, D.R., Ko, J.H., Lee, S.A., Lee, K.-I. and Hwang, I.T. (2015) An Alternative Path for the Preparation of Triacetylcellulose from Unrefined Biomass. Advances in Chemical Engineering and Science, 5, 33-42. http://dx.doi.org/10.4236/aces.2015.51004 
gy platform based on renewable sources, is a major step towards sustainability and is now generally recognized as a worldwide goal [1]-[4].

Material recovery from conversion of agricultural solid wastes into potential construction products has not only benefited the environment but also preserved natural resources. Empty fruit bunch (EFB) is one of such solid wastes generated in oil palm plantations. Many plantations use a small amount for their own internal use, but a large portion is put aside, either biodegrading into compost, or at times burnt to avoid space loss by storage. Therefore, there is a substantial amount of EFB left unused. Hence, it has been verified in engineering properties that construction products made from EFB satisfy the requirement of consumers' trend using products made from eco-friendly and natural waste [5].

Wood and cotton are the major resources for all cellulose products such as paper, textiles, construction materials, and cardboard, as well as cellulose derivatives, such as cellulose esters and ethers. Cellulose acetate (CA) is one of the most important cellulose derivatives which are extensively used in several activities (coatings, membranes, cigar filters, etc.) because of its low-cost, toughness, gloss, high transparency, natural feel, and other favorable aesthetic properties. One of its main applications nowadays is the production of membranes for separation processes such as hemodialysis, reverse osmosis and gas separation. A variety of raw materials such as cotton, recycled paper, crop straw, wood pulp, corncob, corn fiber, rice hulls, and bacterial cellulose have been used to make cellulose acetate. The triacetyl cellulose (TAC) optical film is primarily prepared from cotton due to its low degree of crystallinity, orientation, and low impurity. There are numerous publications and patents on the preparation and utilization of cellulose acetate [6]-[8].

Cellulose acetate is produced by cellulose acetylation, in which cellulose reacts in the presence of acetic anhydride that is used as acetylating agent, acetic acid used as a solvent, and sulfuric acid or perchloric acid used as catalyst. To separate cellulose from lignocellulosic biomass, the most prevalent process is still chemical pulping, which accounts for more than $70 \%$ of worldwide production of pulp. Chemical pulping includes the kraft, sulfite, soda, and organosolv processes, among which kraft pulping accounts for $80 \%$ of chemical pulping. The clean separation of the major components of lignocellulosic biomass (cellulose, lignin, and hemicellulose), using a viable and environmentally-friendly method without loss of quality of the products, has been focus of much attention because the technologies currently used in cellulose processing are decidedly non-green. However, it is extremely difficult to dissolve cellulose in water and most common organic solvents because of their stiff molecules and close chain packing via numerous inter-molecular and intra-molecular hydrogen bonds. Therefore, the multistep and polluting viscose process has long occupied the leading position in the regenerated cellulose (RC) industry [9] [10].

The use of ionic liquids (ILs) as cellulose solvent, in particular for the regeneration of the polysaccharide, was published. The use of ILs in the field of cellulose chemistry opens up a broad variety of new opportunities. ILs have gained increasing attention as green, multi-use reaction media, as well as solvents for electrochemistry and chemistry. ILs are also currently being investigated for a variety of bio-applications including use as media for biocatalytic reactions, biosensors, and protein stabilization. ILs have more or less generally been defined as salts which melt below $100^{\circ} \mathrm{C}$, with some further suggestions that they must be "composed entirely of ions". Room temperature ILs, which are considered as desirable green solvents, have been used to replace the organic solvent in a wide range due to their advantages such as width of liquid range, excellent dissolution ability, being free from the effect of vapor pressure, and ease of recycling. Furthermore, ILs may be easily modified through changing the structure of cations or anions, which will broaden their application fields. Recently, ILs have been used to dissolve native cellulose. It has been found that cellulose can be dissolved without derivatization in high concentrations using 1-butyl-3-methylimidazolium (BMIMCl) chloride as the solvent [9] [11] [12].

In the present article, we describe the new root for the preparation of TAC from unrefined biomass (Bagasse, Japanese red pine, Hybrid poplar, Tulip tree, Oak tree, Rice hulls, Palm Empty Fruit Bunch) by ILs. The process comprises the steps of 1) preparing a source of unrefined biomass powder, 2) dissolving the unrefined biomass into ILs to form a cellulose solution, 3) separation and regeneration of cellulose from lignocellulosic biomass dissolved in ILs, and also in situ modification of cellulose to TAC (Figure 1).

\section{Materials and Methods}

\subsection{Materials}

Natural state itself of biomass (Bagasse, Tulip tree, Hybrid poplar, Oak tree, Japanese red pine, Rice hull, Empty 
Fruit Bunches) were purchased and dried in a vacuum oven at $60^{\circ} \mathrm{C}$ for $24 \mathrm{~h}$ and milled in a ball mill to pass through $250 \mu \mathrm{m}$ screen (Figure 2). The milled samples were stored at room temperature. Acetic anhydride, acetic acid, sulfuric acid, anhydrous magnesium acetate, sodium hydroxide, hydrochloric acid, and dichloromethane were obtained from Sigma-Aldrich Co.

\subsection{Screening of ILs Dissolving Biomass}

Twenty-five ILs (Table 1) were screened for dissolving activity against cellulose of unrefined 8 biomasses. Each $0.2 \mathrm{~g}$ of biomass powder was dissolved in clear vials with $2.8 \mathrm{~g}$ of ILs under $95^{\circ} \mathrm{C}, 120 \mathrm{rpm}$ stirring water bath for $3 \mathrm{~h}$ and kept under $65^{\circ} \mathrm{C}$ heating oven for overnight. IL selection was conducted by visual rating as just within the boundary of transparency.

\subsection{Selective Separation and Regeneration of Cellulose from Unrefined Biomass}

A weighed amount of IL (1-butyl-3-methylimidazolium chloride) was added to clear glass vials equipped with a magnetic stirrer and placed into a heating water bath at $95^{\circ} \mathrm{C}-105^{\circ} \mathrm{C} .2 .5-20 \mathrm{~g}$ of biomass powder were added discretely into the vials. The mixture was stirred for dissolution until the solution was just within the boundary of transparency. The solution of biomass in ILs were sucked out with pipette and spit into water like a thread solidified. The solid phase of cellulose was obtained in the form of regenerating cellulose and dried in an oven at $60^{\circ} \mathrm{C}$ for $24 \mathrm{~h}$ or freeze dried before using as a starting material. In this way the regeneration of cellulose was obtained at room temperature. X-ray diffraction patterns were obtained using a XRD-6000 Shimadzu with $\mathrm{CuK} \alpha$ radiation from $5^{\circ}$ to $50^{\circ}$.

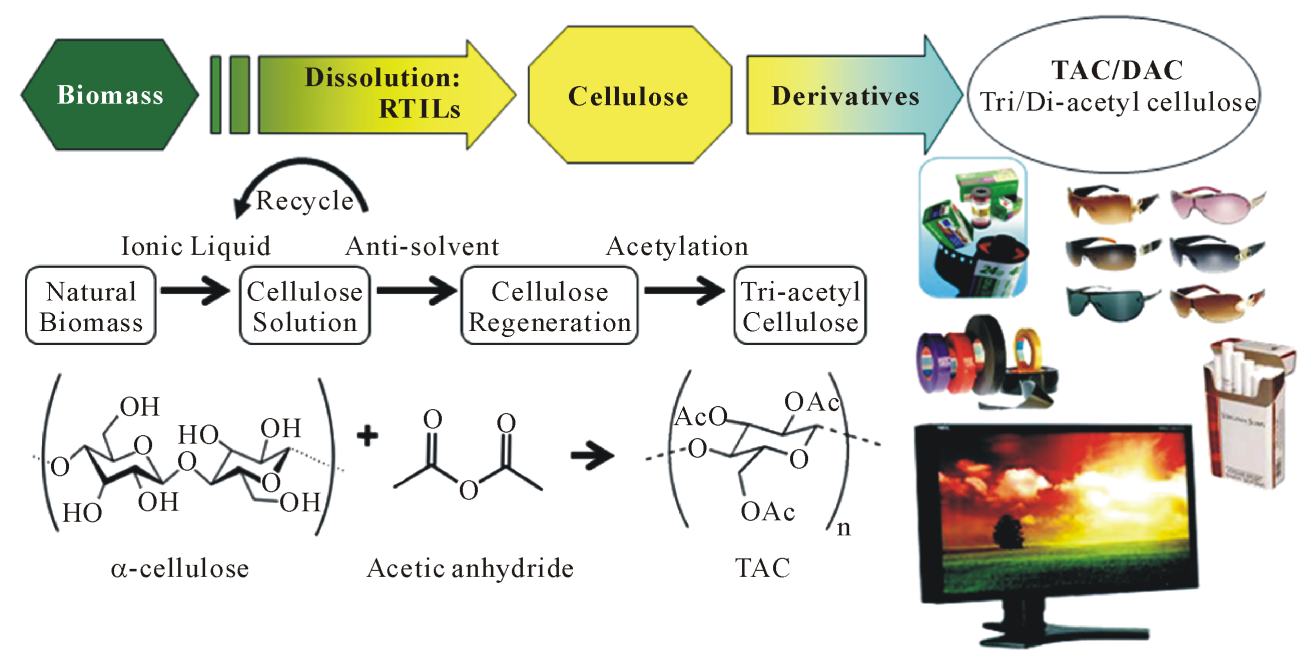

Figure 1. Graphical description of the new root for the preparation of TAC from unrefined biomass.

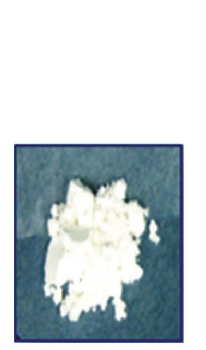

Cellulose

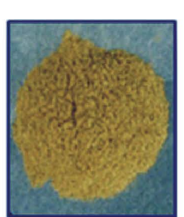

Bagasse

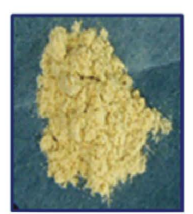

Tulip Tree

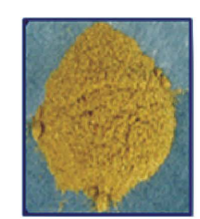

Corn stover

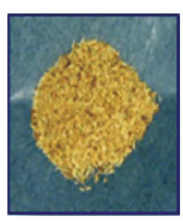

Oak

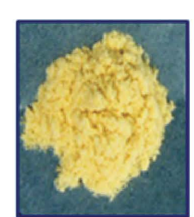

Red Pine

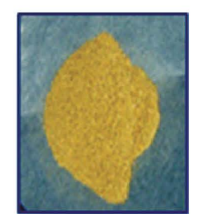

Rice Hulls

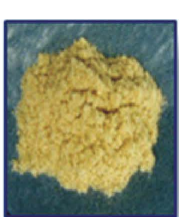

Hybrid Poplar

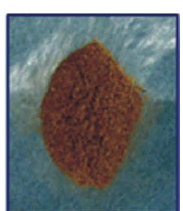

EFB

Figure 2. The milled samples of biomass passed through $250 \mu \mathrm{m}$ sieve. 
Table 1. Twenty-five ionic liquids used in this study.

\begin{tabular}{|c|c|c|c|}
\hline No & Ionic liquids & \multicolumn{2}{|c|}{ Status } \\
\hline 1 & 1-Ethyl-3-methyl-imidazolium-acetate [EMIMAc] & $\geq 90 \%$ & Liquid \\
\hline 2 & 1-Butyl-3-methyl-imidazolium-acetate [BMIMAc] & $\geq 95 \%$ & Liquid \\
\hline 3 & 1-Ethyl-3-methyl-imidazolium-chloride [EMIMCl] & $\geq 95 \%$ & Solid \\
\hline 4 & 1-Butyl-3-methyl-imidazolium-chloride [BMIMCl] & $\geq 95 \%$ & Solid \\
\hline 5 & 1-Methyl-imidazolium-chloride [MIMCl] & $\geq 95 \%$ & Solid \\
\hline 6 & 1-Ethyl-2,3-dimethyl-imidazolium-ethyl sulfate [EMMIMES] & $\geq 95 \%$ & Solid \\
\hline 7 & 1,2,3-Trimethyl-imidazolium-methyl sulfate [MMMIMMS] & $\geq 95 \%$ & Solid \\
\hline 8 & 1-Ethyl-3-methyl-imidazolium-ethyl sulfate [EMIMES] & $\geq 95 \%$ & Liquid \\
\hline 9 & 1-Allyl-3-methyl-imidazolium-chloride [AMIMCl] & $\geq 97 \%$ & Solid \\
\hline 10 & 1-Benzyl-3-methyl-imidazolium-chloride [BeMIMCl] & $\geq 97 \%$ & Jelly \\
\hline 11 & 1-Hexyl-3-methyl-imidazolium-chloride [HeMIMCl] & $\geq 95 \%$ & Jelly \\
\hline 12 & 1-Methyl-3-octyl-imidazolium-chloride [MOIMCl] & $\geq 95 \%$ & Jelly \\
\hline 13 & 1-Ethyl-3-methyl-imidazolium-tosylate [EMIMTo] & $\geq 95 \%$ & Liquid \\
\hline 14 & 1-Ethyl-1-methyl-pyrrolidinium-bromide [EMPYBr] & $\geq 95 \%$ & Solid \\
\hline 15 & 1-Ethyl-3-methyl-imidazolium-bromide [EMIMBr] & $\geq 95 \%$ & Solid \\
\hline 16 & 1-Butyl-1-methyl-pyrrolidinium-chloride [BMPYCl] & $\geq 95 \%$ & Solid \\
\hline 17 & 1-Butyl-2,3-dimethy-imidazolium-chloride [BMMIMCl] & $\geq 95 \%$ & Solid \\
\hline 18 & N-Butyl-pyridinium-chloride [BPyCl] & $\geq 95 \%$ & Solid \\
\hline 19 & 3-Methyl-N-butyl-pyridinium-chloride [MBPyCl] & $\geq 95 \%$ & Solid \\
\hline 20 & 1-Ethyl-imidazolium-nitrate [EIMNi] & $\geq 98 \%$ & Liquid \\
\hline 21 & 1-Methyl-imidazolium-bromide [MIMBr] & $\geq 98 \%$ & Solid \\
\hline 22 & 1-Methyl-imidazolium-chloride [MIMCl] & $\geq 98 \%$ & Solid \\
\hline 23 & 1-Ethyl-imidazolium-bromide [EIMBr] & $\geq 98 \%$ & Solid \\
\hline 24 & 1-Ethyl-imidazolium-chloride [EIMCl] & $\geq 98 \%$ & Solid \\
\hline 25 & 1,2-Dimethy-imidazolium-chloride [MMIMCl] & $\geq 98 \%$ & Solid \\
\hline
\end{tabular}

\subsection{Synthesis of Cellulose Acetate}

Forty $\mathrm{ml}$ of Glacial acetic acid was added to $2 \mathrm{~g}$ of cellulose regenerated, and this mixture was stirred for $30 \mathrm{~min}$ at room temperature. Then, a solution containing $0.3 \mathrm{ml}$ of $\mathrm{H}_{2} \mathrm{SO}_{4}$ and $17.5 \mathrm{ml}$ of acetic anhydride was added to the mixture, which was stirred for $6 \mathrm{~h}$ at room temperature. Insoluble materials were filtered off and the solution was left to stand. Distilled water was added to this clear solution until no more precipitate was formed. The predipitates were vacuum filtered and washed with distilled water until the material was neutral. The produced cellulose acetate was dried in an oven for $90 \mathrm{~min}$ at $105^{\circ} \mathrm{C}$.

\subsection{NMR Analysis}

${ }^{1} \mathrm{H}$ NMR \& ${ }^{13} \mathrm{C}$ NMR spectra were recorded at $500 \mathrm{MHz}$ on a Jeol Eclipse FT $500 \mathrm{MHz}$ spectrometer in $\mathrm{CDCl}_{3}$ as a solvent using TMS as internal standard and chemical shifts were expressed as $\delta$ in ppm; coupling constants $\mathrm{J}$ are given in $\mathrm{Hz}$. 


\section{Results and Discussion}

\subsection{Screening of ILs Dissolving Biomass}

For the preparation of triacetylcellulose (TAC) directly from unrefined biomass by the use of ILs, twenty-five ILs were screened for dissolving the natural state of biomass (Bagasse, Tulip tree, Hybrid poplar, Oak tree, Japanese red pine, Rice hull, Empty Fruit Bunch) at $95^{\circ} \mathrm{C}$ stirring condition. We tried to dissolve all of the biomass powder in ILs used but the solubility was diverse. Even though the standard cellulose dissolved in ILs used, not all ILs were dissolved completely. Eight ILs among 25 ILs, [EMIMAc], [BMIMAc], [EMIMCl], [BMIMCl], [AMIMCl], [BeMIMCl], [HeMIMCl], and [MOIMCl], were selected as an effective dissolving ILs for cellulose powder at $90^{\circ} \mathrm{C}$. Table 2 shows appropriate ILs to each biomass selected, and common ILs to unrefined biomass

Table 2. Selection of ILs s to cellulose and 7 biomass powder at $90^{\circ} \mathrm{C}$.

\begin{tabular}{|c|c|c|c|c|c|c|c|c|}
\hline \multirow{2}{*}{ No. } & \multicolumn{8}{|c|}{ Dissolution Activity (10\% wt/v) } \\
\hline & CEL & BAG & TUL & POP & OAK & PIN & RIC & EFB \\
\hline 1 & $\mathrm{O}$ & $\mathrm{O}$ & $\mathrm{O}$ & $\mathrm{O}$ & $\mathrm{O}$ & $\mathrm{O}$ & $\mathrm{O}$ & $\mathrm{O}$ \\
\hline 2 & $\mathrm{O}$ & $\mathrm{O}$ & $\mathrm{O}$ & $\mathrm{O}$ & $\mathrm{O}$ & $\mathrm{O}$ & $\mathrm{O}$ & $\mathrm{O}$ \\
\hline 3 & $\mathrm{O}$ & $\mathrm{O}$ & $\mathrm{O}$ & $\mathrm{O}$ & $\mathrm{O}$ & $\mathrm{O}$ & $\mathrm{O}$ & $\mathrm{O}$ \\
\hline 4 & $\mathrm{O}$ & $\mathrm{O}$ & $\mathrm{O}$ & $\mathrm{O}$ & $\mathrm{O}$ & $\mathrm{O}$ & $\mathrm{O}$ & $\mathrm{O}$ \\
\hline 5 & $\mathrm{X}$ & $\mathrm{X}$ & $\mathrm{X}$ & $\mathrm{X}$ & $\mathrm{O}$ & $\mathrm{O}$ & $\mathrm{O}$ & $\mathrm{O}$ \\
\hline 6 & $\mathrm{X}$ & $\mathrm{X}$ & $\mathrm{X}$ & $\mathrm{X}$ & $\mathrm{X}$ & $\mathrm{X}$ & $\mathrm{X}$ & $\mathrm{X}$ \\
\hline 7 & $\mathrm{X}$ & $\mathrm{X}$ & $\mathrm{X}$ & $\mathrm{X}$ & $\mathrm{X}$ & $\mathrm{X}$ & $\mathrm{X}$ & $\mathrm{X}$ \\
\hline 8 & $X$ & $X$ & $X$ & $X$ & $\mathrm{X}$ & $X$ & $X$ & $\mathrm{X}$ \\
\hline 9 & $\mathrm{O}$ & $\mathrm{O}$ & $\mathrm{O}$ & $\mathrm{O}$ & $\mathrm{O}$ & $\mathrm{O}$ & $\mathrm{O}$ & $\mathrm{O}$ \\
\hline 10 & $\mathrm{O}$ & $\mathrm{O}$ & $\mathrm{O}$ & $\mathrm{O}$ & $\mathrm{O}$ & $\mathrm{O}$ & $\mathrm{O}$ & O \\
\hline 11 & $\mathrm{O}$ & $\mathrm{O}$ & $X$ & $X$ & $\mathrm{O}$ & $\mathrm{X}$ & $\mathrm{X}$ & $\mathrm{X}$ \\
\hline 12 & $\mathrm{O}$ & $\mathrm{O}$ & $X$ & $\mathrm{X}$ & $X$ & $X$ & $X$ & $\mathrm{X}$ \\
\hline 13 & $X$ & $X$ & $X$ & $X$ & $X$ & $X$ & $X$ & $\mathrm{X}$ \\
\hline 14 & $\mathrm{X}$ & $X$ & $X$ & $X$ & $X$ & $\mathrm{X}$ & $\mathrm{X}$ & $\mathrm{X}$ \\
\hline 15 & $X$ & $X$ & $X$ & $X$ & $\mathrm{X}$ & $X$ & $X$ & $\mathrm{X}$ \\
\hline 16 & $X$ & $\mathrm{O}$ & $\mathrm{O}$ & $\mathrm{O}$ & $X$ & $\mathrm{X}$ & $X$ & $\mathrm{X}$ \\
\hline 17 & $X$ & $\mathrm{O}$ & $X$ & $X$ & $X$ & $X$ & $X$ & $\mathrm{X}$ \\
\hline 18 & $X$ & $X$ & $\mathrm{O}$ & $\mathrm{X}$ & $\mathrm{X}$ & $X$ & $X$ & $\mathrm{X}$ \\
\hline 19 & $\mathrm{X}$ & $X$ & $\mathrm{O}$ & $\mathrm{O}$ & $X$ & $\mathrm{X}$ & $\mathrm{X}$ & $\mathrm{X}$ \\
\hline 20 & $\mathrm{X}$ & $\mathrm{X}$ & $\mathrm{X}$ & $\mathrm{X}$ & $X$ & $\mathrm{X}$ & $X$ & $\mathrm{X}$ \\
\hline 21 & $\mathrm{X}$ & $X$ & $X$ & $X$ & $X$ & $X$ & $X$ & $\mathrm{X}$ \\
\hline 22 & $\mathrm{X}$ & $\mathrm{X}$ & $X$ & $\mathrm{X}$ & $\mathrm{X}$ & $\mathrm{X}$ & $\mathrm{X}$ & $\mathrm{X}$ \\
\hline 23 & $X$ & $X$ & $X$ & $X$ & $\mathrm{X}$ & $\mathrm{X}$ & $X$ & $\mathrm{X}$ \\
\hline 24 & $\mathrm{O}$ & $\mathrm{O}$ & $\mathrm{O}$ & $\mathrm{O}$ & $\mathrm{O}$ & $\mathrm{O}$ & $\mathrm{O}$ & $\mathrm{O}$ \\
\hline 25 & $X$ & $X$ & $\mathrm{X}$ & $X$ & $X$ & $X$ & $\mathrm{X}$ & $\mathrm{X}$ \\
\hline
\end{tabular}

CEL, cellulose; BAG, bagasse; TUL, tulip tree; POP, hybrid poplar; OAK, oak tree; PIN, Japanese red pine; RIC, rice hull; EFB, Palm Empty Fruit Bunch; O, dissolve; X, very low or not dissolve. 
dissolving were [EMIMAc], [BMIMAc], [EMIMCl], [BMIMCl], [AMIMCl], [BeMIMCl] and [EIMCl]. Additionally, [MIMCl], [HeMIMCl], [MOIMCl], [BMPYCl], [BMMIMCl], [BPyCl], and [MBPyCl] were selected for some case of biomass, but not appropriate to all biomass tested. Among these ILs selected, [BMIMCl] showed the best dissolubility not only to the standard cellulose but also to all of the natural biomass tested.

A huge variety of ILs is known today and the number of low melting organic salts is growing rapidly. Nevertheless, according to the literature, ILs with ammonium cations, pyridinium cations, and imidazolium cations are able to dissolve cellulose. Only organic salts with asymmetric cations give melts, which can properly interact with the cellulose backbone. Phosphonium and sulfonium salts are not suitable as cellulose solvents up to now. Dissolution of cellulose in pyridinium salts is combined with degradation if no protective gas is applied. There is no clear theory concerning the interaction between the ILs and the polymer. Still, NMR spectroscopy and structural studies of interaction $\mathrm{Cl}-\mathrm{OH}-\mathrm{Cellulose}$ need to discuss, and cannot explain the fact that only ILs with nitrogen-containing cations are able to dissolve cellulose. No measurements are known for ILs with acetate as counter ion, which dissolve cellulose even better than the chloride. Recently formate-, methyl-phosphate-, and dicyanoamide-containing solvents were described as cellulose solvents. Thus, the dissolution mechanism is still a matter of ongoing research [2] [13]-[20]. There are many literatures about the synthesis and characteristics of new ILs, cellulose dissolution, and transformation to various cellulose derivatives. However, we were curious about the direct extraction or dissolution of the cellulose itself from natural biomass with ILs.

\subsection{Selective Separation and Regeneration of Cellulose from Unrefined Biomass}

As expected, [BMIMCl] gave the best results of ILs for dissolving the natural biomass (Bagasse, Corn stover, Japanese red pine, Hybrid poplar, Tulip tree, Oak tree, Rice hull, Empty Fruit Bunches) with their different colors (Figure 3). A fairly good dissolution was found for other ILs selected. Dissolution of bagasse and corn stover showed dark brown color better than other biomass dissolutions. The dissolved cellulose could be regenerated in a variety of forms, such as fibers, films, beads, etc., by addition of a cellulose anti-solvent which is soluble with the IL. Same to the cellulose regeneration, the dissolution of biomass in ILs were sucked out with pipette tips and spit it into water like thread solidification (Figure 4). In this process, hemicelluloses are accompanied with cellulose but not lignin. Cellulose regeneration and filtration with anti-solvent could be separated from hemicelluloses and lignin [11] [19] [20].

The XRD patterns of EFB celluloses regenerated by ILs are shown in Figure 5. In contrast with the sharp diffraction peaks for the standard cellulose, the EFB celluloses spectrum shows no sharp peaks indicating a decrease of crystallinity and a transition in the structure of the cellulose from crystalline to amorphous region. The standard cellulose shows diffraction peaks at $14.9^{\circ}, 16.5^{\circ}$, and $22.5^{\circ}$ which are characteristic of the crystalline form of cellulose. After regeneration, broad peaks are seen at about $20^{\circ}$ and $22^{\circ}$, which may be due to the damage to the hydrogen-bond in cellulose network during regeneration [21]-[23].

These results are indicating that the cellulose of natural biomass can be directly dissolved in specific ILs without acid/base pretreatment and be easily regenerated by precipitation upon addition of water or other common solvents without severe degradation of the cellulose. Of the ILs we studied, the best results were obtained for 1-butyl-3-methylimidazolium chloride $\left[\mathrm{C}_{4} \mathrm{mim}\right] \mathrm{Cl}$, which was reported by other studies on the dissolution of

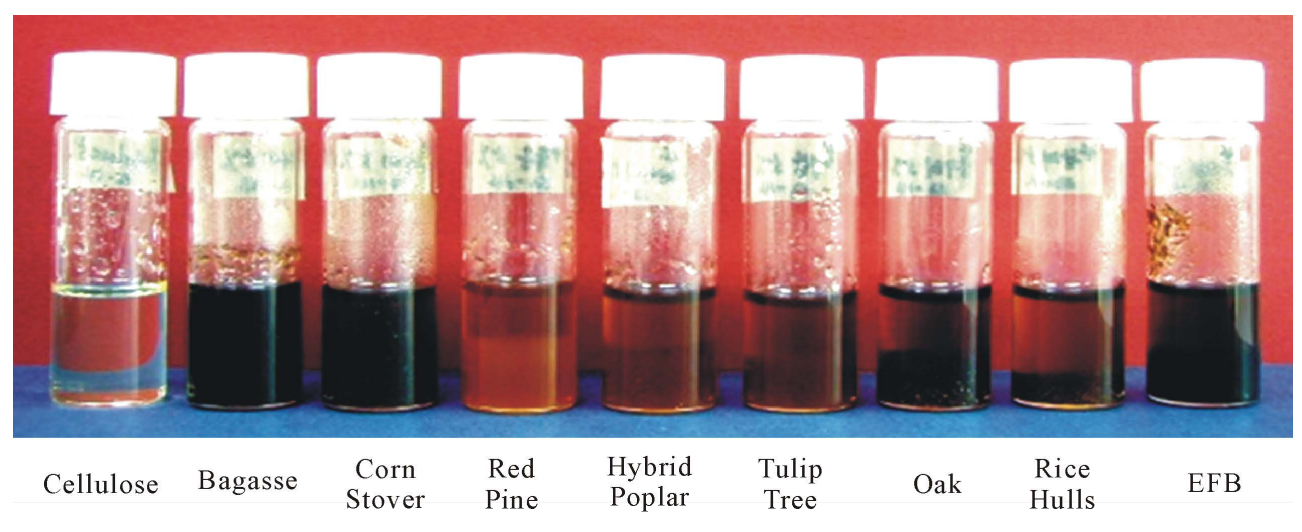

Figure 3. Dissolution of biomass in IL [BMIMCl]. 


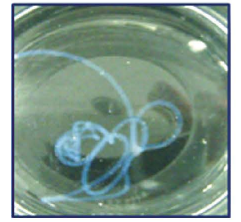

Cellulose

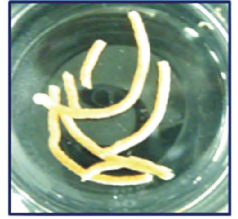

Bagasse

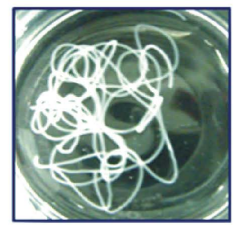

Tulip Tree

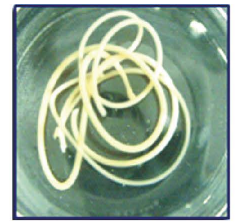

Corn stover

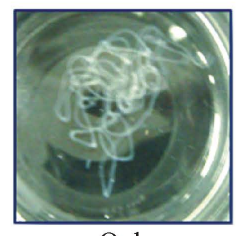

Oak

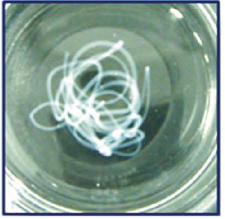

Red Pine

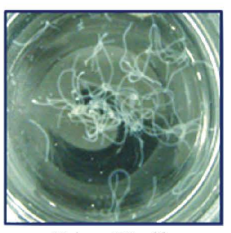

Rice Hulls

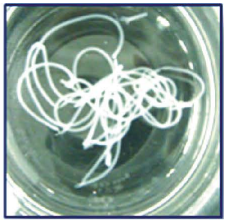

Hybrid Poplar

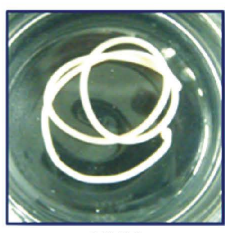

EFB

Figure 4. Thread-like forms of cellulose regeneration from biomass dissolution in ionic liquids.

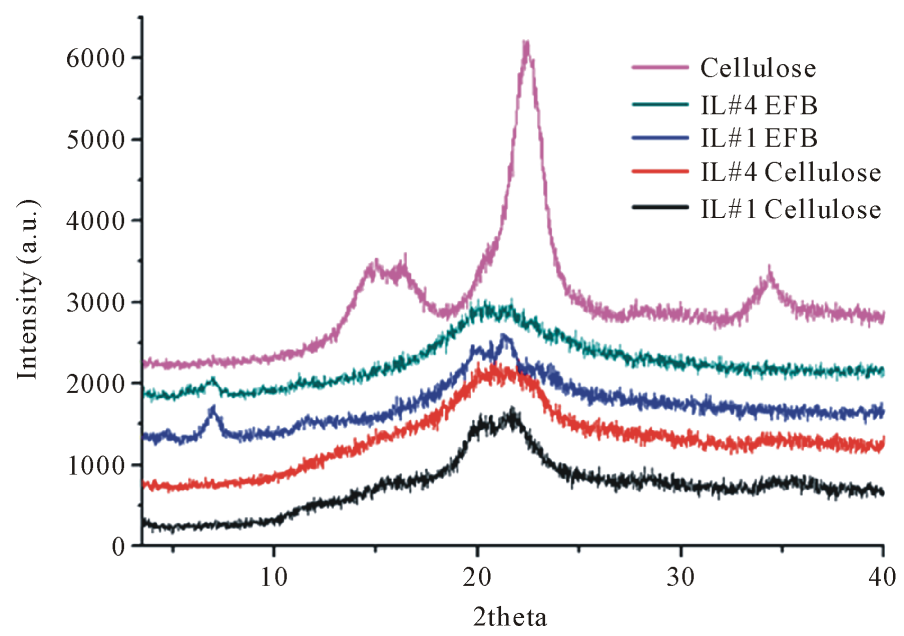

Figure 5. XRD patterns analysis of cellulose regenerated from biomass dissolution in ILs.

cellulose in ILs. The use of such anions resulted in primarily hydrophilic salts, and therefore the regeneration of cellulose from the IL solution was simply carried out by the addition of water to the solution. As a further proof of true dissolution, the dissolved cellulose was reconstituted in amorphous or cellulose II form, distinct from the native cellulose I form [6] [14].

Nevertheless, the most promising ILs for the modification of cellulose is 1-alkyl-3-methylimidazolium salts. An increasing number of papers appear annually concerning this issue. The results support the assumption that ILs can open up new paths for the shaping of the most abundant, renewable organic compound on earth. Additionally, they could also lead to a first commercially relevant route towards homogeneous cellulose chemistry, which would significantly broaden the number of tailored cellulose derivatives [6].

Of growing interest for the modification reactions of cellulose are solvents that are liquid at room temperature and show low viscosities. These solvents can yield reaction media with high cellulose contents, which still can be handled [11] [12].

\subsection{Synthesis of Cellulose Acetate and Characterization}

The acetylating of the cellulose regenerated from the biomass EFB dissolution in ILs was conducted as the method described by Rodrigues Filho et al. (2005) and characterized by NMR. The degree of substitution (DS) was determined by proton NMR, and by titration with aqueous sodium hydroxide solution. In the NMR method, we used the ratio of the seven cellulose proton absorbance in the range of 3.5 - $5.1 \mathrm{ppm}$ to the absorbance of three methyl protons of acetyl groups in the range of $1.9-2.2 \mathrm{ppm}$. DS was calculated by 1/3 of the three methyl pro- 
tons of acetyl group absorbance between 1.9 and 2.2 ppm divided by $1 / 7$ of the total cellulose $\mathrm{CH}$ proton absorbance between 3.5 and $5.1 \mathrm{ppm}$. Excess acetic anhydride was used and acetylation proceeded to the maximum extent to yield cellulose acetate having a degree of substitution of 2.93 from EFB sources with drastically reducing the number of steps currently required to produce this derivative from raw materials itself (Figure 6). In this research, we synthesize TAC after regenerating EFB cellulose dissolved in ILs. However, acetylating synthesis could be started from dissolution in ILs without regeneration, because of the typical procedure for preparation of TAC in IL and solvent recycling schemes have been known already [11]-[14] [21] [22].

Generally, the acetylating conversion of cellulose has been made from starting substrate of cellulose separated from cellulose containing biomass after various pretreatment. Its derivatives, like cellulose esters and ethers,
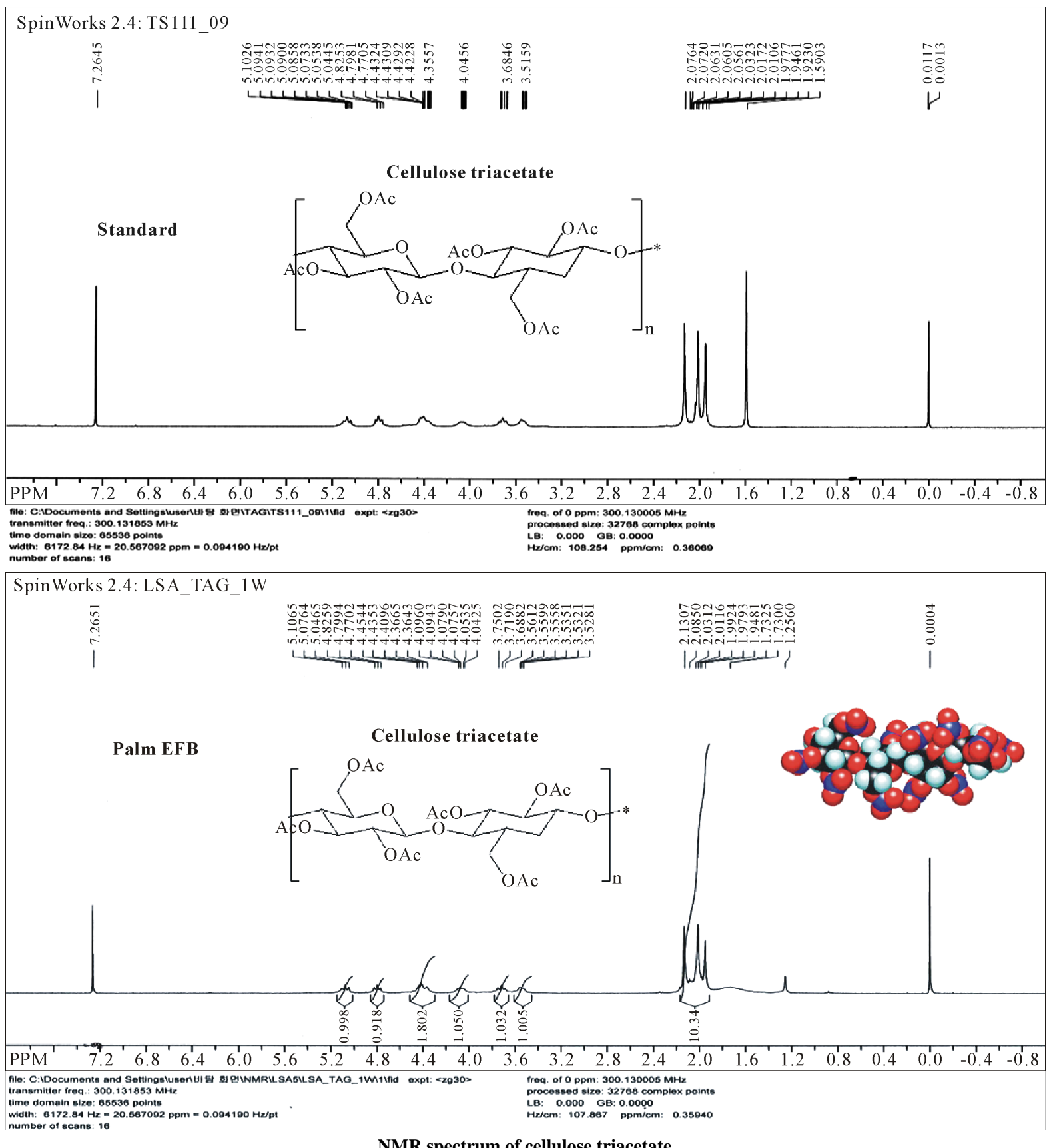

NMR spectrum of cellulose triacetate

Figure 6. NMR analysis pattern of cellulose triacetate from palm EFB. 
have important applications in our daily life such as in textile, pharmaceutical, beauty, food and packaging industries. Wood pulp is main raw material for cellulose. It can also be extracted from algae, bacteria. Corn fiber, rice hulls, and wheat straw contain about $15 \%, 36 \%$ and $45 \%$ cellulose, respectively [23]. However, corn fiber and wheat straw were acetylated without pretreatment; the recovered yields of cellulose acetate were extremely low. When untreated corn fiber was used as the starting material only, $1.8 \%$ conversion was achieved. Based on the amount of the cellulose in corn fiber, a conversion of about $12 \%$ was achieved. Untreated wheat straw gave the lowest conversion of only $0.5 \%$. This is somewhat surprising since wheat straw contains about $30 \%$ cellulose [24]. Pretreatment of the lignocellulose may be essential for making cellulose acetate. The acetylating conversion of cellulose in rice hulls, wheat straw, and corn fiber increased to about $25 \%$ for all substrates after the dilute acid pretreatment at a moderate temperature. The increase in conversion is probably due to the pretreatment removing hemicellulose and other acid soluble materials. The result is an increase in the relative concentration of cellulose in the starting substrate. It is interesting to note that after pretreatment the acetylation conversion is about the same, regardless of the starting material. This may be due to remaining cellulose having the same reactivity. It is assumed that the acetylation reaction would only work on the amorphous cellulose. This would put a theoretical conversion of cellulose to cellulose acetate at about $30 \%$. This means that acetylation reaction of pretreated rice hulls, wheat straw, and corn fiber may be near the theoretical limit of conversion without further treatments on the cellulose to reduce its crystallinity. Since cellulose fibers are embedded with lignin, this may interfere with the acetylation reaction [8]-[12].

Ionic liquids are being investigated as lignocelluloses deconstruction solvents for a number of reasons. As already mentioned a major and widely highlighted advantage of the IL dissolution process compared to other pretreatment options is its ability to decrystallize the cellulose portion of lignocellulosic biomass and simultaneously disrupt the lignin and hemicelluloses network. More work is needed to improve the efficiency of the conversion. It is also demonstrated that some side reactions have to be considered. The first techno-economical analysis modeling of ionic liquid deconstruction has determined that among the investigated variables the order of importance/sensitivity is ionic liquid price > biomass loading > recycling rate. In addition, the ability to sell the lignin and/or its products will heavily impact on the process costs. The following list, whilst not exhaustive, contains aspects of ionic liquid pretreatment that should receive attention in the future. Further investigations will help to determine whether the identified challenges of ionic liquid processing of lignocelluloses are inherent disadvantages or can be improved upon by optimization or technical innovation [12].

\section{Conclusion}

The cellulose in natural biomass was converted into cellulose acetate with direct dissolved and separated cellulose from biomass of Bagasse, Tulip tree, Hybrid poplar, Oak tree, Japanese red pine, Rice hull, and Empty Fruit Bunches without other pretreatments. Eight ILs among 25 ILs tested, [EMIMAc], [BMIMAc], [EMIMCl], [BMIMCl], [AMIMCl], [BeMIMCl] and [EIMCl], were selected as effective common dissolving solvents for the natural state of biomass. An alternative path for the preparation of triacetylcellulose (TAC) from unrefined biomass Palm Empty Fruit Bunch (EFB) has been found with the method of comprising separation and regeneration of cellulose from lignocellulosic biomass dissolved in ionic liquid BMIMCl, and also modification of cellulose to TAC. The triacetylcellulose with a degree of substitution of 2.93 was obtained by the reaction of acetic anhydride at $55^{\circ} \mathrm{C}$ with drastically reducing the number of steps currently required to produce this derivative from raw materials itself and characterized using NMR analysis. More work is needed to improve the efficiency of the conversion. This method may improve the cost efficiency into value-added cellulose acetate.

\section{Acknowledgements}

We would like to acknowledge the financial support from the R\&D Convergence Program of MSIP (Ministry of Science, ICT and Future Planning) and ISTK (Korea Research Council for Industrial Science and Technology) of Republic of Korea (Grant B551179-10-03-00).

\section{References}

[1] Ragauskas, A.J., Williams, C.K. and Davison, B.H. (2006) The Path Forward for Biofuels and Biomaterials. Science, 311, 484-488. http://dx.doi.org/10.1126/science.1114736 
[2] Sun, N., Rodríguez, H., Rahman, M. and Rogers, R.D. (2011) Where Are Ionic Liquid Strategies Most Suited in the Pursuit of Chemicals and Energy from Lignocellulosic Biomass? Chemical Communications, 47, 1405-1421. http://dx.doi.org/10.1039/c0cc03990j

[3] Huang, Y.-B. and Fu, Y. (2013) Hydrolysis of Cellulose to Glucose by Solid Acid Catalysts. Green Chemistry, 15, 1095-1111. http://dx.doi.org/10.1039/c3gc40136g

[4] Konur, O. (2012) The Scientometric Evaluation of the Research on the Production of Bioenergy from Biomass. Biomass and Bioenergy, 47, 504-515. http://dx.doi.org/10.1016/j.biombioe.2012.09.047

[5] Uemura Y., Omar, W., Othman, N.A., Yusup, S. and Tsutsui, T. (2013) Torrefaction of Oil Palm EFB in the Presence of Oxygen. Fuel, 103, 156-160. http://dx.doi.org/10.1016/j.fuel.2011.11.018

[6] Liebert, T. and Heinze, T. (2008) Interaction of Ionic Liquids with Polysaccharides 5. Solvents and Reaction Media for the Modification of Cellulose. BioResources, 3, 576-601.

[7] Fan, X., Liu, Z.-T. and Liu, Z.-W. (2010) Preparation and Application of Cellulose Triacetate Microspheres. Journal of Hazardous Materials, 177, 452-457. http://dx.doi.org/10.1016/j.jhazmat.2009.12.054

[8] Meireles, C.S., Filho, G.R., Ferreira Jr., M.F., Cerqueira, D.A., Assunção, R.M.N., Ribeiro, E.A.M., Poletto, P. and Zeni, M. (2010) Characterization of Asymmetric Membranes of Cellulose Acetate from Biomass: Newspaper and Mango Seed. Carbohydrate Polymers, 80, 954-961. http://dx.doi.org/10.1016/j.carbpol.2010.01.012

[9] Biswas, A., Saha, B.C., Lawton, J.W., Shogren, R.L. and Willett, J.L. (2006) Process for Obtaining Cellulose Acetate from Agricultural By-Products. Carbohydrate Polymers, 64, 134-137. http://dx.doi.org/10.1016/j.carbpol.2005.11.002

[10] Fan, X.S., Liu, Z.-W., Lu, J. and Liu, Z.-T. (2009) Cellulose Triacetate Optical Film Preparation from Ramie Fiber. Industrial Engineering Chemistry Research, 48, 6212-6215. http://dx.doi.org/10.1021/ie801703x

[11] Xie, H., King, A., Kilpelainen, I., Granstrom, M. and Argyropoulos, D.S. (2007) Thorough Chemical Modification of Wood-Based Lignocellulosic Materials in Ionic Liquids. Biomacromolecules, 8, 3740-3748.

[12] Gericke, M., Fardim, P. and Heinze, T. (2012) Ionic Liquids-Promising but Challenging Solvents for Homogeneous Derivatization of Cellulose. Molecules, 17, 7458-7502. http://dx.doi.org/10.3390/molecules17067458

[13] Swatloski, R.P., Spear, S.K., Holbrey, J.D. and Rogers, R.D. (2002) Dissolution of Cellulose with Ionic Liquids. Journal of the American Chemical Society, 124, 4974-4975. http://dx.doi.org/10.1021/ja025790m

[14] Brandt, A., Gräsvik, J., Hallett, J.P. and Welton, T. (2013) Deconstruction of Lignocellulosic Biomass with Ionic Liquids. Green Chemistry, 15, 550-583. http://dx.doi.org/10.1039/c2gc36364j

[15] Groff, D., George, A., Sun, N., Sathitsuksanoh, N., Bokinsky, G., Simmons, B.A., Holmes, B.M. and Keasling, J.D. (2013) Acid Enhanced Ionic Liquid Pretreatment of Biomass. Green Chemistry, 15, 1264-1267. http://dx.doi.org/10.1039/c3gc37086k

[16] Li, C. and Zhao, Z.K. (2007) Efficient Acid-Catalyzed Hydrolysis of Cellulose in Ionic Liquid. Advanced Synthesis \& Catalysis, 349, 1847-1850. http://dx.doi.org/10.1002/adsc.200700259

[17] Qi, H., Yang, Q., Zhang, L., Liebert, T. and Heinze, T. (2011) The Dissolution of Cellulose in NaOH-Based Aqueous System by Two-Step Process. Cellulose, 18, 237-245. http://dx.doi.org/10.1007/s10570-010-9477-8

[18] El Seoud, O.A., Koschella, A., Fidale, L.C., Dorn, S. and Heinze, T. (2007) Applications of Ionic Liquids in Carbohydrate Chemistry: A Window of Opportunities. Biomacromolecules, 8, 2629-2647. http://dx.doi.org/10.1021/bm070062i

[19] Rantwijk, F. and Sheldon, R.A. (2007) Biocatalysis in Ionic Liquids. Chemical Reviews, 107, 2757-2785. http://dx.doi.org/10.1021/cr050946x

[20] Zhang, H., Wu, J., Zhang, J. and He, J. (2005) 1-Allyl-3-methylimidazolium Chloride Room Temperature Ionic Liquid: A New and Powerful Nonderivatizing Solvent for Cellulose. Macromolecules, 38, 8272-8277. http://dx.doi.org/10.1021/ma0505676

[21] Filho, G.R., Monteiro, D.S., Meireles, C.S., Assunção, R.M.N., Cerqueira, D.A., Barud, H.S., Ribeiro, S.J.L. and Messadeq, Y. (2008) Synthesis and Characterization of Cellulose Acetate Produced from Recycled Newspaper. Carbohydrate Polymers, 73, 74-82. http://dx.doi.org/10.1016/j.carbpol.2007.11.010

[22] Barud, H.S., Araújo Jr., A.M., Santos, D.B., Assunção, R.M.N., Meireles, C.S., Cerqueira, D.A., Filho, G.R., Ribeiro, C.A., Messaddeq, Y. and Ribeiro, S.J.L. (2008) Thermal Behavior of Cellulose Acetate Produced from Homogeneous Acetylation of Bacterial Cellulose. Thermochimica Acta, 471, 61-69. http://dx.doi.org/10.1016/j.tca.2008.02.009

[23] Saha, B.C., Iten, L.B., Cotta, M.A. and Wu, Y.V. (2005) Dilute Acid Pretreatment, Enzymatic Saccharification, and Fermentation of Rice Hulls to Ethanol. Biotechnology Progress, 21, 816-822. http://dx.doi.org/10.1021/bp049564n

[24] Saha, B.C. (2004) Lignocellulose Biodegradation and Applications in Biotechnology. In: Saha, B.C. and Hayashi, K., Eds., Lignocellulose Biodegradation, American Chemical Society, Washington DC, 1-34. http://dx.doi.org/10.1021/bk-2004-0889 
Scientific Research Publishing (SCIRP) is one of the largest Open Access journal publishers. It is currently publishing more than 200 open access, online, peer-reviewed journals covering a wide range of academic disciplines. SCIRP serves the worldwide academic communities and contributes to the progress and application of science with its publication.

Other selected journals from SCIRP are listed as below. Submit your manuscript to us via either submit@scirp.org or Online Submission Portal.
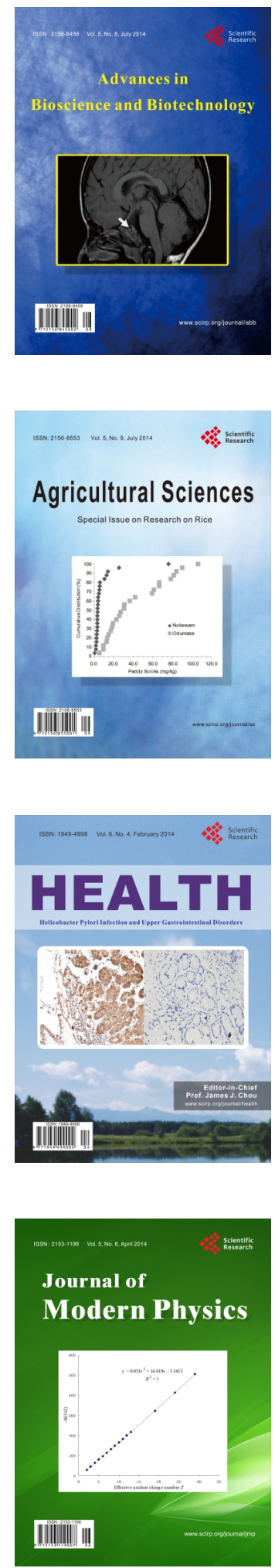
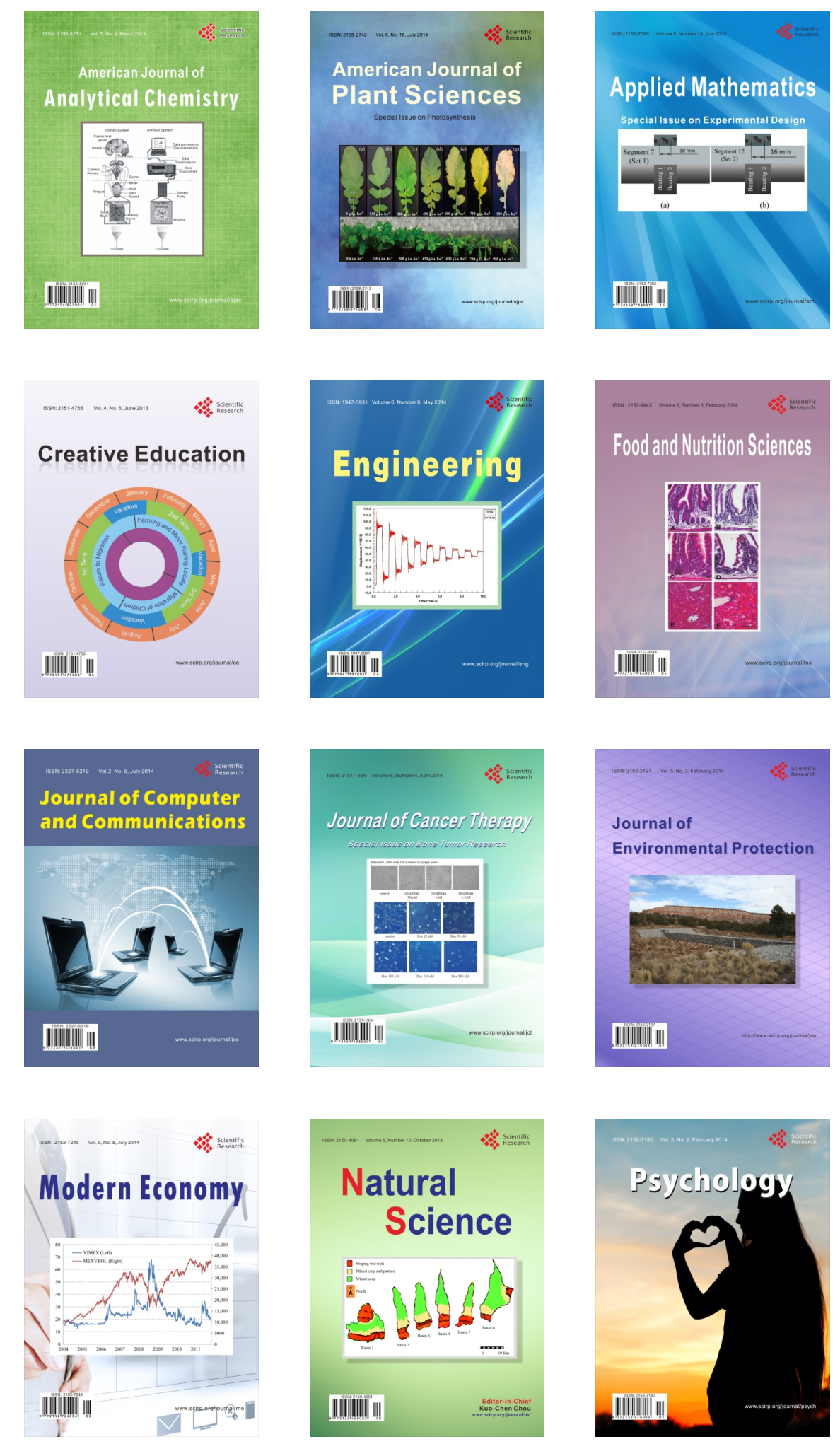